\title{
Diversity of the gut microbiome in three grasshopper species using 16S rRNA and determination of cellulose digestibility
}

Jian-Mei Wang ${ }^{1}$, Jing Bai ${ }^{1}$, Fang-Yuan Zheng ${ }^{1}$, Yao Ling ${ }^{1}$, Xiang Li $^{1}$, Jing Wang ${ }^{1}$, Yong-Chao Zhi ${ }^{1}$, Xin-Jiang Li Corresp. 1

${ }^{1}$ The Key Laboratory of Zoological Systematics and Application, College of Life Science, Institute of Life Science and Green Development, Hebei University, Baoding, hebei, China

Corresponding Author: Xin-jiang Li

Email address: lixinjiang@hbu.cn

Background: Grasshoppers are typical phytophagous pests, and they have large appetites with high utilization of plants fibers, the digestion of which may depend on the microorganisms in their intestines. Grasshoppers have the potential to be utilized in bioreactors, which could improve straw utilization efficiency in the future. In this study, we describe the gut microbiome in three species of grasshoppers, Oedaleus decorus asiaticus, Aiolopus tamulus and Shirakiacris shirakii, by constructing a 16S rDNA gene library and analyzed the digestibility of cellulose and hemicellulose in the grasshoppers by using moss black phenol colorimetry and anthrone colorimetry. Results:There were 509,436 bacterial OTUs (Operational Taxonomic Units) detected in the guts of all the grasshoppers sampled. Among them, Proteobacteria and Firmicutes were the most common, Aiolopus tamulus had the highest bacterial diversity, and Shirakiacris shirakii had the highest bacterial species richness. The intestinal microflora structure varied between the different species of grasshopper, with Aiolopus tamulus and Shirakiacris shirakii being the most similar. Meanwhile, the time at which grasshopper specimens were collected also led to changes in the intestinal microflora structure in the same species of grasshoppers. Klebsiella may form the core elements of the microflora in the grasshopper intestinal tract. The digestibility of cellulose/hemicellulose among the three species grasshoppers varied (38.01/24.99\%, 43.95/17.21\% and 44.12/47.62\%). LEfSe analysis and Spearman correlation coefficients showed that the hemicellulosic digestibility of Shirakiacris shirakii was significantly higher than that of the other two species of grasshopper, which may be related to the presence of Pseudomonas, Stenotrophomonas, Glutamicibacter, Corynebacterium, and Brachybacterium in Shirakiacris shirakii intestinal tract.

Conclusion:The intestinal microbial communities of the three grasshoppers species are similar on phylum level, but the dominant genera of different species grasshoppers are different. The cellulose digestibility of the three species of grasshoppers is relatively high, 
understanding of the structure and function of the grasshopper intestinal microflora will facilitate further research and the utilization of intestinal microorganisms in the future. 


\title{
1 Diversity of the gut microbiome in three grasshopper species using 16S
}

\section{rRNA and determination of cellulose digestibility}

\author{
Jian-Mei Wang, Jing Bai, Fang-Yuan Zheng, Yao Ling, Xiang Li, Jing Wang, Yong-Chao Zhi, Xin-jiang Li*
}

The Key Laboratory of Zoological Systematics and Application, College of Life Science, Institute of Life Science and Green Development, Hebei University, Baoding, Hebei province, China

Corresponding Author:

Xin-jiang Li

Hebei University, Baoding, Hebei province, 071002, China

Email address: lixinjiang@hbu.edu.cn

\section{Abstract:}

Background: Grasshoppers are typical phytophagous pests, and they have large appetites with high utilization of plants fibers, the digestion of which may depend on the microorganisms in their intestines. Grasshoppers have the potential to be utilized in bioreactors, which could improve straw utilization efficiency in the future. In this study, we describe the gut microbiome in three species of grasshoppers, Oedaleus decorus asiaticus, Aiolopus tamulus and Shirakiacris shirakii, by constructing a 16S rDNA gene library and analyzed the digestibility of cellulose and hemicellulose in the grasshoppers by using moss black phenol colorimetry and anthrone colorimetry.

Results: There were 509,436 bacterial OTUs (Operational Taxonomic Units) detected in the guts of all the grasshoppers sampled. Among them, Proteobacteria and Firmicutes were the most common, Aiolopus tamulus had the highest bacterial diversity, and Shirakiacris shirakii had the highest bacterial species richness. The intestinal microflora structure varied between the different species of grasshopper, with Aiolopus tamulus and Shirakiacris shirakii being the most similar. Meanwhile, the time at which grasshopper specimens were collected also led to changes in the intestinal microflora structure in the same species of grasshoppers. Klebsiella may form the core elements of the microflora in the grasshopper intestinal tract. The digestibility of cellulose/hemicellulose among the three species grasshoppers varied (38.01/24.99\%, 43.95/17.21\% and 44.12/47.62\%). LEfSe analysis and Spearman correlation coefficients showed that the hemicellulosic digestibility of Shirakiacris shirakii was significantly higher than that of the other two species of grasshopper, which may be related to the presence of Pseudomonas, Stenotrophomonas, Glutamicibacter, Corynebacterium, and Brachybacterium in Shirakiacris shirakii intestinal tract.

Conclusion: The intestinal microbial communities of the three grasshoppers species are similar on phylum level, but the dominant genera of different species grasshoppers are different. The cellulose digestibility of the three species of grasshoppers is relatively high, which may be correlated with the presence of some gut microbiome. Increasing the understanding of the structure and function of the grasshopper intestinal microflora will facilitate 
further research and the utilization of intestinal microorganisms in the future.

\section{Introduction}

Grasshoppers (Orthoptera: Acridoidea) are the main pests in agriculture, cattle grazing and forestry. Grasshoppers require a large quantity of gramineous plants to obtain the nutrients and water necessary for their survival, especially in their adult stage. The food selectivity of grasshoppers is affected by many factors. As far as plants themselves are concerned, the factors that affect grasshoppers' food selectivity include cellulose, water, carbohydrate and protein contents (Ibanez et al., 2013). Wheat seedlings, which have a moisture content of $89.819 \%-93.326 \%$, are rich in protein, vitamins, minerals, and other nutrients (Min et al., 2017) and are easy to cultivate, making them good fodder for grasshoppers bred in laboratories.

Cellulose and hemicellulose are the main components of many biomass (Mueller-Hagedorn \& Bockhorn, 2007). Due to the limitation of the lignin-hemicellulose, most of the biomass are difficult to be decomposed and utilized (Thompson et al., 2003). Many factors, like lignin content, crystallinity of cellulose, and particle size, limit the digestibility of the hemicellulose and cellulose present in the lignocellulosic biomass (Hendriks \& Zeeman, 2009). At present, cellulose and hemicellulose are increasingly widely used (Xiong et al., 2005), and their efficient utilization is of great practical significance to reduce the burning of straw and promote the sustainable development of agriculture and animal husbandry.

The gut microbiome is a general term for all the microorganisms inhabiting the digestive tract of animals (Rangberg et al., 2012) and contains the most concentrated set of interactions among all symbiotic microorganisms in animals (Guo et al., 2015). In the process of evolution, insects and intestinal microorganisms interact, cooperate and coevolve. Insects secrete digestive enzymes by means of symbiotic microorganisms in the body to better digest food and obtain energy needed for their own growth and development (Mason, Jones \& Felton, 2019). It is possible to contrive a species-wide metabolic interaction network of the termite gutmicrobiome in order to have a system-level understanding of metabolic communication. Kundu et al.(2019) have elucidated 15 crucial hemicellulolytic microbes and their corresponding enzyme machinery (Kundu et al., 2019). At present, no insect has been found to be able to completely digest lignocellulose food via cellulase and hemicellulase secreted by itself (Sun \& Chen, 2010).

Compared with termites and cockroaches, grasshoppers have a very sparse microbiome(Dillon \& Dillon, 2004). But these microorganisms play an important role in the grasshopper digestive tract. Studies have shown that changing the structure of the intestinal microbial community can affect the survival rate of grasshoppers(Tan et al., 2020); Dillon et al. (2002) have discovered that locust gut bacteria were responsible for the production of components of the locust cohesion pheromone (Dillon, Vennard \& Charnley, 2002). At present, research on the intestinal microbial community of insects mainly focuses on certain economic insects, including silkworm,

Ceroplastes japonica, and others, to improve the intestinal environment to reduce silkworm diseases or to increase the wax secretion of Ceroplastes japonica (Yi et al., 2001; Bei et al., 2005). In addition, other insects, such as ants and longicorn beetles, have been studied for their role in decomposing lignocellulose (Zhang et al., 2005).

There are few studies on the composition of the grasshopper intestinal microflora structure, community diversity and functional bacteria. In addition, current research is based on traditional culture methods or traditional molecular biology techniques, and grasshopper intestinal microorganisms have not yet been

Peer) reviewing PDF | (2020:05:49060:2:0:NEW 19 Sep 2020) 
78

79

80

81

82

83

84

85

86

87

88

89

90

91

92

93

94

95

96

97

98

99

100

101

102

103

104

105

106

107

108

109

110

111

112

113

114

115

116

thoroughly investigated. In this study, the intestinal bacterial community structures of three species grasshoppers were studied by constructing a 16S rDNA library technology, and the abundance and phylogenesis of these bacteria were analyzed to obtain better information on grasshopper intestinal microbial diversity, providing a theoretical basis for clarifying the mechanism of cellulose degradation in grasshopper, and further study the relationship between intestinal microorganisms and pest control. At the same time, the digestibility of cellulose and hemicellulose in the grasshoppers were determined by using moss black phenol colorimetry and anthrone colorimetry, providing basic data for the development of a cellulose and hemicellulose digestion bioreactor, as well as a feasible method for determining insects' cellulose and hemicellulose digestibility.

\section{Materials and methods}

\section{Specimen collection}

Adults of Oedaleus decorus asiaticus Bey-bienko, 1941, Aiolopus tamulus Fabricius, 1789 and Shirakiacris shirakii Bolívar, 1914, were collected from Baoding City, Hebei Province, China in July to November 2018 (Table 1).

\section{Intestinal microbial diversity of grasshoppers}

Total DNA of the intestinal contents of the 3 species grasshoppers was extracted, with each species having 3 groups of samples, totaling 9 sample groups. The sample numbers are shown in Table 1. Total DNA of the 9 sample groups was used as templates, and PCR was carried out with universal primers targeting the 16S rDNA $\mathrm{V} 3+\mathrm{V} 4$ region of prokaryotes. After the PCR products passed quality tests, they were detected by an Illumina HiSeq 2500 sequencer (at Biomarker Technologies Corporation), and the data were processed and analyzed by Uparse and QIIME software (Caporaso et al., 2010).

\section{Sample treatment}

The collected and classified living grasshoppers were placed in cages without access to food for 2 days to remove their intestinal contents. The grasshoppers to be tested were washed repeatedly with sterile water, placed in a $75 \%$ alcohol solution for $2 \mathrm{~min}$, washed with sterile water, irradiated with ultraviolet light for 3-5 minutes, and dissected grasshoppers under sterile conditions. The entire intestinal tract was removed, and the midgut and hindgut parts were separated; placed in labeled, sterilized $1.5 \mathrm{~mL}$ centrifuge tubes; and kept at $80^{\circ} \mathrm{C}$ for later use.

\section{Extraction of total DNA from the intestinal contents}

Total DNA of the intestinal contents of grasshoppers was extracted using the PowerSoil DNA Isolation Kit according to the manufacturer's protocol, and the quality and quantity of DNA were evaluated by the 260 $\mathrm{nm} / 280 \mathrm{~nm}$ and $260 \mathrm{~nm} / 230 \mathrm{~nm}$ ratios, respectively. DNA was then stored at $-80^{\circ} \mathrm{C}$ until further processing.

For each individual sample, the $16 \mathrm{~s}$ rDNA V 3 + V 4 region was amplified using the $338 \mathrm{~F}$ (5'ACTCTACGGAGAGCA-3') and 806 R (5'-GGACTACHVGGGTWTCTAT-3') primers (Mori et al., 2014). PCR was performed in a total reaction volume of $20 \mu \mathrm{L}: \mathrm{H}_{2} \mathrm{O}, 13.25 \mu \mathrm{L} ; 10 \times$ PCR ExTaq Buffer, $2.0 \mu \mathrm{L}$; DNA template $(100 \mathrm{ng} / \mathrm{mL}), 0.5 \mu \mathrm{L}$; primer1 $(10 \mathrm{mmol} / \mathrm{L}), 1.0 \mu \mathrm{L}$; primer2 $(10 \mathrm{mmol} / \mathrm{L}), 1.0 \mu \mathrm{L} ; \mathrm{dNTP}, 2.0 \mu \mathrm{L}$; and ExTaq $(5 \mathrm{U} / \mathrm{mL}), 0.25 \mu \mathrm{L}$. After an initial denaturation at $95^{\circ} \mathrm{C}$ for $5 \mathrm{~min}$, amplification was performed with 30 cycles of incubations for $30 \mathrm{sec}$ at $95^{\circ} \mathrm{C}, 20 \mathrm{sec}$ at $58^{\circ} \mathrm{C}$, and $6 \mathrm{sec}$ at $72^{\circ} \mathrm{C}$, followed by a final 
117 extension at $72^{\circ} \mathrm{C}$ for $7 \mathrm{~min}$. The amplified products were then purified and recovered using $1.0 \%$ agarose gel

118 electrophoresis. Finally, all the PCR products were quantified by Quant-iT ${ }^{\mathrm{TM}}$ dsDNA HS Reagent and pooled

119 together. High-throughput sequencing analysis of bacterial rRNA genes was performed on the purified, pooled

120 samples using the Illumina HiSeq 2500 platform $(2 \times 250$ pairedends $)$ at Biomarker Technologies Corporation,

121 Beijing, China. Finally, library construction and sequencing were performed by Beijing Biomarker

122 Technologies Co. Ltd.

\section{Bioinformatics analysis}

124 Bioinformatics analysis in this study was completed on the Biomarker Cloud Platform (www.biocloud.org).

125 The original data obtained by sequencing were spliced by FLASH software. Then, raw tags were filtered and

126 clustered. Sequences were removed from inclusion according to the following criteria: the average mass of

127 bases was less than 20; the reads were low quality; the sequences contained primer mismatches; the sequences

128 were less than $350 \mathrm{bp}$ in length; and the sequences could not be spliced. UCHIME, a tool included in mothur

129 (http://drive5.com/uchime), was used to remove chimeras and generate valid data. OTUs were taxonomically

130 annotated based on the Silva (bacteria) and UNITE (fungi) taxonomic databases. The denoised sequences were

131 clustered using USEARCH (version 10.0), and tags with similarity $\geq 97 \%$ were regarded as OTUs. Taxonomy

132 was assigned to all OTUs by searching against the Silvadatabases (http://www.arb-silva.de.) using uclust

133 within QIIME (Edgar, 2010).

134 Digestibility of wheat seedlings in grasshoppers

135 Collection and treatment of samples

136 Grasshoppers collected in the field were separately packed in insect rearing cages, and each cage contained

13710 individuals that were fed wheat seedlings (The wheat variety was Triticum aestivum Linnaeus,1753). After

138 consecutively feeding for 3 days (no dung was collected during the period, and the wheat seedlings provided

139 sufficient nutrition), grasshoppers were fasted for 2 days. A layer of white plastic foam was spread on the

140 bottom of the cages to facilitate the collection of excrement (Wang et al., 2008). During the experiment, the

141 fresh weight of wheat seedlings fed each time was recorded, and the feces and residual wheat seedlings were

142 dried to a constant weight at $70^{\circ} \mathrm{C}$ and recorded (using an electrothermal constant temperature blast drying

143 oven, Shanghai Flyover Experimental Instrument Co., Ltd. DGG-9030A). The dry-fresh ratio of wheat

144 seedlings was determined to calculate the dry weight of the wheat seedlings before the experiment (Wang,

145 1997). The collected feces were dried to a constant weight, pulverized, and filtered with a 40 mesh sieve.

146 The wheat seedlings were rapidly dehydrated by steam de-enzyming (Sun, 2014), dried at $70^{\circ} \mathrm{C}$ until a

147 constant weight, crushed, and filtered with a 40 mesh sieve for later use.

148 Determination of cellulose and hemicellulose content

149 Samples were prepared by weighing out $0.800 \mathrm{~g}$ of each sample, to which $8 \mathrm{~mL} 72 \% \mathrm{H}_{2} \mathrm{SO}_{4}$ was added, 150 followed by shaking. Samples were placed in a water bath at $30^{\circ} \mathrm{C}$ for $1 \mathrm{~h}$, followed by the addition of $8 \mathrm{~mL}$

$1514 \% \mathrm{H}_{2} \mathrm{SO}_{4}$, and were then returned to the water bath for $45 \mathrm{~min}$. Finally, $224 \mathrm{~mL}$ of distilled water was added,

152 and the samples shaken well before being placed into conical flasks in an electric heating pressure steam

153 sterilization pot (LS-30 type of Shanghai Bosun Industrial Co., Ltd.). Samples were then heated to a

154 temperature of $121^{\circ} \mathrm{C}$ for $1 \mathrm{~h}$ and filtered to obtain sample solutions.

155 One milliliter of this sample solution was diluted appropriately, and $1 \mathrm{~mL}$ of the diluted sample solution was

Peer] reviewing PDF | (2020:05:49060:2:0:NEW 19 Sep 2020) 
156 added to $1 \mathrm{~mL}$ of anthrone reagent and $3 \mathrm{~mL}$ of $80 \%$ sulfuric acid, mixed well, and boiled at $100^{\circ} \mathrm{C}$ for $5 \mathrm{~min}$.

157 After cooling to room temperature, absorbance at $620 \mathrm{~nm}$ was measured, with the sugar concentration

158 calculated according to the glucose standard regression equation and then multiplied by 0.9 (Zhang et al.,

159 2010).

160 One milliliter of the sample solution was diluted appropriately, and $1 \mathrm{~mL}$ of the diluted sample solution was

161 add to $2 \mathrm{~mL}$ of $\mathrm{A}$ reagent and $0.134 \mathrm{~mL}$ of $\mathrm{B}$ reagent and boiled at $100^{\circ} \mathrm{C}$ for 20 min after fully mixing.

162 Absorbance at $660 \mathrm{~nm}$ was measured after cooling to room temperature, with the sugar concentration

163 calculated according to the xylose standard regression equation and then multiplied by 0.88 (Zhang et al.,

164 2010).

165 Calculation of the decomposition rates of cellulose and hemicellulose

166 The decomposition rates of cellulose and hemicellulose were calculated after the cellulose and hemicellulose 167 contents of the adult grasshopper feces were determined by the above methods. Statistical analysis of 168 digestibility data was done in SPSS 21.0 software using T-test.

169

170

171

172

173 Note: $c$ is the sugar concentration $(\mathrm{g} / \mathrm{L})$ calculated according to the standard curve, $m$ is the weighed sample 174 mass (g).

175 Correlation between digestibility and microorganism abundance

176 The LefSe analysis and Spearman analysis were performed using R and the Psych, Pheatmap and reshape2 177 package (Kostic et al., 2015) on the Biomarker Cloud Platform. The correlation between cellulose digestibility 178 and intestinal microbial diversity of grasshoppers was established.

179

\section{Results}

181 Intestinal microbes in grasshoppers

182 Evaluation of sequencing quality

A total of 702,445 paired-end reads were obtained by sequencing the 9 pooled samples. and 512,109 clean tags were generated after splicing and filtering the paired-end reads. A minimum of 51,643 clean tags were generated for each sample, with an average of 56,901 clean tags. The proportion of effective sequences was $99.48 \%$. The sequencing accuracy of the samples was high and met the standard requirements. Effective tags were the number of effective sequences after filtering chimeras from the clean tags. The number of sequences and the proportion for each sample are shown in Table 2 below.

To identify the number of common and unique OTUs among samples, a Venn diagram was used, which intuitively reflects the coincidence of OTUs among samples. As shown in Figure 1 (A), there were 37 species 
193 Shirakiacris shirakii, 11 species specific to Oedaleus decorus asiaticus, and 13 species specific to Aiolopus

194 tamulus. Further analysis of the identifies of the bacteria common to the three grasshopper species indicated

195 that they were mainly composed of two families of Enterobacteriaceae and Enterococcaceae, as shown in

196 Figure 1(B), with a relative abundance of $97.57 \%$, indicating that these two families may form the core

197 microflora in the grasshopper intestinal tract.

\section{8 a-diversity analysis}

199

200

201

202

203

204

205

206

207

208

209

210

211

212

213

214

215

216

217

218

219

220

221

222

223

224

225

226

227

228

229

230

231

As shown in Figure 2(A), the rarefaction curves of 9 samples tended to be flat over an increasing number of sequences. The Shannon, Simpson, Chao1, and ACE indices, as well as others, were used to express the $\alpha$ diversity of the microorganisms in the samples. As shown in Table 3, the coverage of the nine samples was relatively high, reaching $99.97 \% \sim 99.99 \%$. The above results show that the sequencing data were reasonable and that the vast majority of bacteria in the samples were detected. Different from the rarefaction curve, the species accumulation curve reflects whether the number of samples was sufficient and whether the information covered all the annotated species. As shown in Figure 2(B), as the sample number increased, the cumulative curve and the common quantity curve tended to be flat, which demonstrates that the new and common species detected in the sample were both approaching saturation, indicating that the sample size was sufficient and could be used for diversity and abundance analysis.

The $\alpha$-diversity of 9 samples varied according to the individual. In the three samples of Aiolopus tamulus, the Shannon index of At1 and At2 was much higher than that of At3, while the Simpson index of At3 was the opposite, indicating that the species diversity in samples At1 and At2 was higher than that in At3. Among the three samples of Oedaleus decorus asiaticus, the Shannon index of Od3 was much higher than that of Od1 and Od2, while the Simpson index of Od3 was much lower than that of the other two samples. For the three samples of Shirakiacris shirakii, the Shannon index and Simpson index were not significantly different, which may be related to the difference in the collection time (Table 1).

The average value of each index of three samples from the same species was calculated and then used to compare and analyze the $\alpha$-diversity among the different species. The Chao1 index (Figure 2C) of Shirakiacris shirakii was significantly higher than that of Oedaleus decorus asiaticus, and the ACE index (Figure 2D) was the highest in Shirakiacris shirakii, followed by Aiolopus tamulus, which demonstrates that among the three species grasshoppers, the abundance of species in the intestinal tract of Shirakiacris shiraki was significantly higher than that of Oedaleus decorus asiaticus, with Aiolopus tamulus in the middle. The Simpson index (Figure 2E) of Aiolopus tamulus was the smallest, while the index of Shirakiacris shiraki was the largest. The Shannon index (Figure 2F) followed the opposite trend to the Simpson index, which indicated that the species diversity in the intestinal tract of Aiolopus tamulus was the highest, followed by the Oedaleus decorus asiaticus, with Shirakiacris shiraki as the lowest.

\section{$\beta$-Diversity analysis}

Based on pyrosequencing data, PCoA and UPGMA clustering were carried out to determine $\beta$-diversity. As shown in Supplementary figure 1, the smaller the distance between points in the figure, the smaller the difference in the intestinal flora structure, and vice versa. It can be seen from the figure that the difference in the intestinal microflora structure between the three samples of Shirakiacris shiraki and two of the samples of Aiolopus tamulus was relatively small, while difference in the intestinal microflora structure between one 
232

233

234

235

236

237

238

239

240

241

242

243

244

245

246

247

248

249

250

251

252

253

254

255

256

257

258

259

260

261

262

263

264

265

266

267

268

269

270

sample and the remaining two samples for both Oedaleus decorus asiaticus and Aiolopus tamulus was relatively large. The difference in the intestinal microflora structure among the three samples of Shirakiacris shiraki was not large. In addition, the hierarchical cluster tree (Figure 3A) shows that the microbial communities of the three species grasshoppers are divided into three groups: (1) group I includes samples A1 and A2 and sample O3, (2) group II includes samples O1 and O2 and sample A3, and (3) group III includes all the samples of Shirakiacris shiraki. In addition, the distance between group II and group III was closer, that is, the composition of the intestinal microflora is more similar between those two groups. Taken together, these results show that the intestinal microflora of different species of grasshoppers vary from one another. The intestinal microflora of Aiolopus tamulus and Shirakiacris shiraki are more similar. At the same time, different sampling times will also lead to the recombination of microbial communities.

NMDS (Nonmetric Multidimensional Scaling) analysis can reflect the differences between groups or within groups according to the distribution of samples. As shown in Figure 3B, the stress value is less than 0.01, which indicates that the analysis result is extremely reliable. In the figure, it can be seen that there is a large difference in the intestinal community between one sample the remaining two samples for both Oedaleus decorus asiaticus and Aiolopus tamulus, which is related to the different collection times of the samples, indicating that a difference in collection time leads to changes in the microbial community structure of the same species. The three samples of Shirakiacris shiraki along with two samples of Aiolopus tamulus are almost coincident, which indicates that the similarity of the intestinal microflora structure between the two groups was relatively high.

As shown in Figure 3C, Ss1, Ss2 and Ss3 were grouped together; At1 and At2 were grouped together; and all (Ss1, Ss2, Ss3 and At2) were grouped with Od3. Od1 and Od2 were grouped with At3. The samples At1 and At2 of Aiolopus tamulus were relatively close to the three samples of Shirakiacris shiraki, which indicates that the intestinal community similarity between Aiolopus tamulus and Shirakiacris shiraki is high, that the difference of the microflora structure between them is relatively small, and that different collection times for the same species can lead to low similarity and large differences in the grasshopper intestinal microflora structure, which is consistent with the above results, indicating that a difference in collection time causes changes in the microbial community structure.

\section{Intestinal microflora structure of the three species grasshoppers}

High-quality sequences obtained from 16S rDNA identification were compared with the database, and a total of 54 genera of 7 phyla, 12 classes, and 20 orders were identified. The composition of each sample is shown in Table 2. Once the average relative abundance of different grasshoppers in the same treatment at each classification level is calculated, the average relative abundance can reflect the content of various intestinal microorganisms at the overall level.

\section{Intestinal microflora structure at the phylum level}

The nine samples At1, At2, At3, Od1, Od1, Od2, Od3, Ss1, Ss2, and Ss3 contained 85.65\%, 83.51\%, $93.45 \%, 89.51 \%, 91.43 \%, 87.32 \%, 86.92 \%, 87.33 \%$, and $87.35 \%$, respectively, of the valid sequences that were able to be annotated at the phylum level. Seven phyla were detected in the nine samples. According to the annotation results of the samples at various classification levels (kingdom, phyla, class, order, family, genus and species), as shown in Figure 4A, Proteobacteria accounted for the highest relative abundance in the three

PeerJ reviewing PDF | (2020:05:49060:2:0:NEW 19 Sep 2020) 
271 species of grasshoppers, Aiolopus tamulus, Oedaleus decorus asiaticus, and Shirakiacris shiraki, at 94.10\%,

$27290.72 \%$ and $93.94 \%$, respectively. The second highest was Firmicutes, accounting for 5.72\%, 8.94\% and

$2735.31 \%$, respectively.Actinobacteria accounted for a relatively high proportion of $0.52 \%$ in the intestinal tract of

274 Shirakiacris shiraki, although less than $0.10 \%$ in the intestinal tracts of the other two species. Cyanobacteria

275 was relatively abundant in the intestinal tract of Oedaleus decorus asiaticus, at $0.26 \%$, while its abundance in

276 the other two species was very small, accounting for $0.01 \%$. Fusobacteria existed in the intestinal tracts of the

277 three species grasshoppers in trace amounts, accounting for less than $0.10 \%$. Bacteroidetes was found in trace

278 amounts in Aiolopus tamulus and Oedaleus decorus asiaticus but was not detected in the intestinal tract of

279 Shirakiacris shiraki. Tenericutes was only found in trace amount in the intestinal tract of Oedaleus decorus

280 asiaticus, at $0.04 \%$, but was not found in the intestinal tracts of the other two grasshoppers. Additionally,

$2810.20 \%$ unassigned microorganisms were present in the intestinal tract of Shirakiacris shiraki that have not

282 previously been studied.

283 It is worth noting that the proportion of Firmicutes in At3 intestinal bacteria was $0.24 \%$, which was much

284 lower than that in At 1 (11.01\%) and At2 (5.91\%) treated with the same method. However, the proportion in

285 sample Od3 (26.74\%) was much higher than that in sample Od1 (0.03\%) and sample Od2 (0.06\%), while the

286 proportion in the three samples Ss1 (3.72\%), Ss2 (1.83\%) and Ss3 (10.36\%) of Shirakiacris shiraki was

287 relatively constant, which could be related to their different collection times, indicating that the abundance of

288 intestinal flora varied over different periods in the same species. Combined with $\alpha$-diversity analysis, these

289 results show that the diversity and abundance of intestinal microflora varied over different periods in the same

290 species.

291 Intestinal microflora structure at genus level

292 At1, At2, At3, Od1, Od2, Od3, Ss1, Ss2 and Ss3 contained 54.57\%, 68.35\%, 93.40\%, 89.35\%, 90.93\%,

$29387.31 \%, 86.08 \%, 85.45 \%$ and $87.30 \%$, respectively, of the valid sequences that could be annotated at the genus

294 level. A total of 54 bacterial genera were detected, of which 24 bacterial genera were common among the three

295 species. As seen in Figure 4B, Klebsiella accounted for the highest proportion of the microbial community in

296 the three grasshopper species. The top 10 abundant bacterial genera (by average relative abundance) for each

297 of the three species of grasshoppers after data standardization are shown in Supplementary Tables 1, 2, and 3.

298 In the three samples of Aiolopus tamulus, the average relative abundance of Klebsiella, Enterococcus and

299 Enterobacter was greater than 1\%, which identifies them as the primary bacteria in the Aiolopus tamulus

300 intestinal tract. The primary bacteria of Oedaleus decorus asiaticus were Klebsiella, Enterococcus, Pantoea,

301 Wolbachia, Enterobacter, and Lactococcus. Klebsiella, Lactococcus, and Staphylococcus were the primary

302 genera of Shirakiacris shiraki. Five bacterial genera were detected only in the intestinal tract of Aiolopus

303 tamulus, namely, Anaerotruncus, Diaphorobacter, Morganella, Proteiniclasticum, and

304 Rikenellaceae_RC9_gut_group. The proportion of these five bacterial genera in the intestinal tract was not

305 more than $0.1 \%$. Among them, Morganella was not detected in the At3 samples, but was detected in the At1

306 and At2 samples, and the remaining 4 genera were detected only in the At3 samples but not in the At 1 and At2

307 samples, indicating that there were significant differences in the intestinal microflora diversity of the same

308 species from different time periods. The genera Sphaerotilus and Spiroplasma were only detected in the

Peer] reviewing PDF | (2020:05:49060:2:0:NEW 19 Sep 2020) 
309

310

311

312

313

314

315

316

317

318

319

320

321

322

323

324

325

326

327

328

329

330

331

332

333

334

335

336

337

338

339

340

341

342

343

344

345

346

347

intestinal tract of Oedaleus decorus asiaticus, and Cronobacter was only detected in Shirakiacris shiraki.

Therefore, the diversity of the intestinal microorganisms varied by grasshopper species.

\section{Digestibility results}

From Table 4, the cellulose digestibility of the three species of grasshoppers were $43.95 \%, 38.01 \%$ and $44.12 \%$, and there was no significant difference ( $>0.05)$ among the three groups. However, the hemicellulose digestibility in Shirakiacris shirakii at $47.65 \%$ was significantly higher $(\mathrm{P}<0.05)$ than that in Aiolopus tamulus (17.21\%) and Oedaleus decorus asiaticus (24.99\%). In addition, the cellulose digestibility in Aiolopus tamulus and Oedaleus decorus was significantly higher than that of hemicellulose, and there was no significant difference between the cellulose and hemicellulose digestibility in Shirakiacris shirakii.

\section{Correlation between digestibility and microorganism abundance}

In view of the fact that Shirakiacris shirakii can be distinguished from the other two species and that the digestibility of hemicellulose is significantly higher in that organism than in the other two species $(\mathrm{P}<0.05)$, we conducted LEfSe analysis (Figure 5, Supplementary figure 2) on the three species and identified Pseudomonas, Stenotrophomonas, Glutamicibacter, Corynebacterium, Brachybacterium and other bacteria genera as biomarkers of group difference. The relative abundance of these identified species in Shirakiacris shirakii is significantly higher than that in the other species, which may be related to the degradation of hemicellulose. To further screen out bacteria related to the degradation rate of cellulose and hemicellulose, we calculated the Spearman correlation coefficients (Figure 6) for the association between the degradation rate and microflora abundance and identified a number of bacteria whose abundance had a high correlation with the degradation rates of cellulose and hemicellulose. Some of the results highly overlap with the LEfSe analysis, suggesting that these bacteria can be used as candidate bacteria for cellulose and hemicellulose degradation.

\section{Discussion}

In this experiment, we constructed a $16 \mathrm{~S}$ rRNA gene library via Illumina MiSeq sequencing and applied it to systematically study the intestinal microflora composition of three grasshopper species for the first time.

Among the different grasshopper species, the abundance and diversity of intestinal microorganisms were varied. Through the analysis of $\alpha$ and $\beta$ diversity, it was found that the diversity of the intestinal microflora in the same species was quite varied depending on the collection time. The grasshoppers in this study were collected from summer and autumn populations from the same location, which meant that there were changes in the host insect habitat. Previous studies have shown that the environmental conditions of the habitat of the host insect can affect the interaction between insects and their symbiotic microorganisms, as well as the species and distribution of symbiotic microorganisms (Schmid et al., 2015), indicating that the diversity and function of microorganisms in the intestinal tract of insects are closely related to the habitat conditions in which the insects live. However, there are few reports on whether changes in the environment of host insects affects the species and community composition of intestinal microorganisms and the specific extent of that impact, which is a problem worthy of further study.

There were differences in the primary intestinal bacteria among the different species of grasshopper, but the abundance of Proteobacteria was the highest in the intestinal bacteria of all three species of grasshopper, followed by Firmicutes. Bacteria of those two phyla accounted for more than $98 \%$ of the total intestinal 
348 bacteria of the three grasshopper species, which was consistent with previous reports on the primary species of 349 insect microbiomes. Previous studies have shown that Proteobacteria are the primary bacteria in the intestinal

350

351

352

353

354

355

356

357

358

359

360

361

362

363

364

365

366

367

368

369

370

371

372

373

374

375

376

377

378

379

380

381

382

383

384

385

386 tract of many insects: Schistocerca gregaria in Orthoptera (Dillon et al., 2010), Acyrthosiphon pisum in Hemiptera, and Ectropis obliqua (Engel \& Moran, 2013) and Spodoptera frugiperda (Gichuhi et al., 2020) in Lepidoptera. Among the Lepidoptera insects studied, the primary bacteria in the intestinal tract of Lymantria dispar, Helicoverpa armigera, Bombyx mori and Plutella xylostella larvae are Proteobacteria and Firmicutes (Zhou et al., 2015; Priya et al., 2012; Broderick et al., 2004).

There was variation in the primary genera in the intestinal tract of the grasshopper species. These primary genera and other less abundant genera all play important roles in the life activities of host insects. The content of Klebsiella in the intestinal tract of the three species grasshoppers in this study was very high, which was similar to the results of Liu (2012) on symbiotic bacteria in the intestinal tract of Locusta migratoria manilensis using DGGE (Liu, 2012). The second most abundant bacteria in our study was Enterococcus. This result is consistent with the previous results where bacteria were found to be the most abundant in the microflora of Schistocerca gregaria. (Lavy et al., 2019). In addition, previous studies have shown that Enterococcus can not only help degrade lignocellulose but can also produce biogenic amines, which have important physiological functions, such as promoting host growth and enhancing metabolism (Shu, $\mathrm{Lu} \& \mathrm{Xu}$, 2011; Shil et al.,2014). Enterococcus may encode 1,4- $\beta$-cellobiosidase, endoglucanase and $\beta$-glucosidase, which are involved in cellulose degradation, and 1,4- $\beta$-xylosidase, which is involved in xylan degradation (Xia et al., 2013; Potrikus \& Breznak, 1977; Warnecke et al., 2007); these factors have functions relating to food digestion and absorption. However, some other reported cellulose-degrading bacteria, such as Enterobacter and Pseudomonas (Bayer, Shoham \& Lamed, 2006; Muhammad et al., 2017), have no significant correlation with cellulose and hemicellulose degradation, and the presence of these bacteria may contribute to eliminating the differences in cellulose digestibility in this study. Acinetobacter participates in host food digestion, degrades harmful compounds, and plays a role in nitrogen transformation (Briones-Roblero et al., 2016; Liu et al., 2016; Mason et al., 2016). Existing studies have shown that Wolbachia plays an important role in the reproductive ability of host insects (Hancock et al., 2011), and whether this genus has an effect on the reproduction of grasshoppers requires further attention.

Since the main food source of grasshoppers is cellulose, it is speculated that the intestinal tract of grasshoppers may contain abundant microorganisms capable of degrading cellulose. Willis et al. (2010) isolated cellulase from the foregut and hindgut of the Carolina wasp Dissosteira carolina, which was highly similar to the $\beta$-1,4-endonuclease of bacteria, fungi and invertebrates, including that secreted by the insects themselves (Willis et al., 2010). Wang et al. (2010) isolated and screened 5 strains of bacteria with cellulose degradation function from the intestinal tract of Yunnanacris yunnaneus, including 4 strains of Bacillus and one strain of Pseudomonas, which had CMC and filter paper enzyme activities of $167 \mu / \mathrm{mLand} 9.8 \mu / \mathrm{mL}$, respectively (Wang et al., 2010). The above studies show that grasshoppers have the ability to degrade cellulose efficiently. In this study, the contents of cellulose and hemicellulose in the wheat seedling and feces of three species of grasshoppers adults were detected by colorimetry, and the decomposition rates of cellulose and hemicellulose were calculated and analyzed. The cellulose digestibility in Aiolopus tamulus and Oedaleus decorus was significantly higher than that of hemicellulose. On one hand, this relates result to the structure and 
387

388

389

390

391

392

393

394

395

396

397

398

399

400

401

402

403

404

405

406

407

408

409

410

411

412

413

414

415

416

417

418

419

420

421

422

423

424

425

composition of cellulose and hemicellulose. Compared with cellulose, hemicellulose has a very complex structure and composition, including xylose, arabinose, mannose and galactose, etc. In the cell wall, hemicellulose is distributed among many celluloses, embedded in the surface of cellulose microfibers and mixed with cellulose. Therefore, only when cellulose is hydrolyzed can hemicellulose be completely hydrolyzed (Vargas, Weiss \& Mcclements, 2007). On the other hand, the difference in cellulose and hemicellulose digestibility relates to the type and quantity of microorganisms in the grasshopper's intestinal tract. Intestinal microorganisms can secrete a variety of cellulose digestive enzymes. The activities of cellulase and hemicellulase determine the grasshopper's ability to digest cellulose and hemicellulose.

The cellulose digestibility in the three species of grasshoppers was not significantly different, $43.95 \%$, $38.01 \%$, and $44.12 \%$, respectively. In a previous study, Li et al. (2000) found that the digestibility of crude fiber in different components of corn straw fed to sheep varied from 34.21\%-61.21\% ( $\mathrm{Li}$ et al.,2000). Fang et al. (2009) studied the utilization rate of different straw diets in Xinjiang cattle and found that the digestibility of acid detergent fiber (ADF) and neutral detergent fiber (NDF) in wheat straw was $35.02 \%$ and $43.86 \%$, respectively, and that the digestibility of ADF and NDF in corn straw was $44.26 \%$ and $51.91 \%$, respectively (Fang et al., 2009). Meanwhile, a study by Zhao (2015) found that the digestibility of cellulose in corn straw by Locusta migratoria manilensis was $15.10 \%$ (Zhao, 2015). Our results showed that the cellulose digestibility in the three species grasshoppers was significantly higher than that of Locusta migratoria manilensis and was close to that of mammals. Whether this difference was related to a difference in the composition of the feeding material needs to be further studied. However, in terms of cellulose digestibility, the intestinal capacity of grasshoppers is very small compared with that of mammals, but their cellulose decomposition rate is close to that of mammals, which indicates that the ability of Aiolopus tamulus, Oedaleus decorus asiaticus and Shirakiacris shirakii to digest cellulose is indeed strong and that studying the cellulose decomposition rate of grasshoppers may be of great value to the development of a cellulose decomposition bioreactor.

Herbivorous insects usually do not directly digest cellulose, or minimally digest cellulose, but mainly digest starch, sugar and protein in food (Douglas, 2009). Moreover, the honey bee gut microbiota digests complex carbohydrates, such as hemicellulose and pectin, thereby acquiring energy(Zheng et al, 2019). These insects are mainly limited by nitrogen intake rather than carbon source (McNeil \& Southwood, 1978). Klebisella plays an important role in ammonia assimilation into amino acids (Senior, 1975), and its negative correlation with the digestion rate may be related to this. Similarly, San et al. (2011)also identified some other bacteria related to nitrogen metabolism, including Staphylococcus, Stenotrophomonas, etc (San et al., 2011). However, it cannot be ignored that this study is consistent with previous studies, i.e., grasshoppers have a strong ability to digest cellulose ( $\mathrm{Su}$ et al., 2014), how much of which is due to the action of their own digestive enzymes and how much of which is due to the contribution of microorganisms needs to be further explored.

Yet, it remains to be seen whether cellulose/hemicellulose digestion in these grasshoppers is exclusively intrinsic or mediated by a combination of intrinsic and bacterial-mediated processes. Until now, there has been no direct evidence that grasshoppers rely entirely on gut microbes to break down cellulose and hemicellulose. For herbivorous insects, the efficiency of decomposition and utilization of cellulose and hemicellulose are largely dependent on gut microbes (Jehmlich et al., 2016). Corynebacterium and Glutamicibacter have been identified from the intestinal bacteria of Shirakiacris shirakii. And Corynebacterium has been reported to be

Peer] reviewing PDF | (2020:05:49060:2:0:NEW 19 Sep 2020) 
426 able to hydrolyze hemicellulose (Buschke, Schröder \& Wittmann, 2011). Glutamicibacter isolated from the

427 intestinal tract of Proisotoma ananevae has strong cellulose degradation ability (Wang et al., 2018).

428 Clavibacter produces cellulase (Waleron et al., 2010) and Brachybacterium can degrade cellulose (Zhang et al.,

429 2007), which supports the results of our correlation analysis. Many insects have intrinsic cellulases (Davison \&

430 Blaxter, 2005), and some insects belonging to Acrididae have cellulase that can break down plant cell

431 walls(Calderon-Cortes et al., 2012).Combined with the results of this article, we can slate a new hypothesis:

432 the intestinal microorganisms of grasshoppers have a great influence on the decomposition of

433 cellulose/hemicellulose.

434

\section{Conclusions}

436 This study analyzed the intestinal microbial diversity of 3 species of grasshoppers, using the method of $16 \mathrm{~S}$

437 rDNA gene library construction. Proteobacteria and Firmicutes are the dominant bacteria in the intestinal

438 microbial communities of the three grasshoppers species. However, the dominant genera of different species

439 grasshoppers are different. Shirakiacris shirakii had the highest bacterial species richness, and Aiolopus

440 tamulus had the highest bacterial diversity. The intestinal microflora structure varied between the different

441 species of grasshoppers, with the intestinal microflora structure of Aiolopus tamulus and Shirakiacris shirakii

442 being the most similar. Meanwhile, the time at which grasshopper specimens were collected also led to

443 changes in the intestinal microflora structure in the same species of grasshoppers.

444 There was no significant difference in cellulose digestibility between the three species of grasshoppers

445 ( $>0.05)$, while the hemicellulose digestibility of Shirakiacris shirakii was significantly higher than Aiolopus

446 tamulus and Oedaleus decorus asiaticus $(\mathrm{P}<0.05)$. In addition, the cellulose digestibility of Aiolopus tamulus

447 and Oedaleus decorus asiaticus was significantly higher than the hemicellulose digestibility.

448 LEfSe analysis and Spearman correlation coefficients showed that the hemicellulosic digestibility of

449 Shirakiacris shirakii was significantly higher than that of the other two species of grasshopper, which may be

450 related to the presence of Pseudomonas, Stenotrophomonas, Glutamicibacter, Corynebacterium, and

451 Brachybacterium in Shirakiacris shirakii intestinal tract.

452 This study lays a foundation for the utilization of garsshoppers intestinal microorganisms in the future.

453

454 Acknowledgments

455 This study is funded by the Natural Science Foundation of Hebei Province (No. C2018201139), Natural

456 Science Foundation of China (No. 31872274, No. 31702043 \& No. 32070473), and Post-graduate's Innovation

457 Fund Project of Hebei University (No. hbu2019ss022). We would like to thank DBMediting for professional

458 English language editing services.

459 References

460 Bayer, E.A., Shoham, Y. \& Lamed, R. 2006. Cellulose-decomposing Bacteria and Their Enzyme Systems. Prokaryotes 2,

461 578-617 DOI 10.1007/0-387-30742-7_19.

462 Bei, S. G., Liu, Y. S. \& Cui, J. X. 2005. Isolation and identification of bacteria from gastrointestinal tract of Ceroplastes

463 japonicus Green. Journal of Shandong Agricultural University (Natural Science) 36, 209-212 DOI 10.3969/j.issn.1000-

$464 \quad 2324.2005 .02 .011$.

Peer) reviewing PDF | (2020:05:49060:2:0:NEW 19 Sep 2020) 
465

466

467

468

469

470

471

472

473

474

475

476

477

478

479

480

481

482

483

484

485

486

487

488

489

490

491

492

493

494

495

496

497

498

499

500

501

502

503

Briones-Roblero, C. I., Rodriguez-Diaz, R., Santiago-Cruz, J. A., Zuniga, G. \& Rivera-Orduna, F. N. 2016. Deradation capacities of bacteria and yeasts isolated from the gut of Dendroctonus rhizophagus (Curculionidae: Scolytinae). Folia Microbiplogica 62, 1-9 DOI 10.1007/s12223-016-0469-4.

Broderick, N. A., Raffa, K. F., Goodman R. M. \& Handelsman J. 2004. Census of the Bacterial Community of the Gypsy Moth Larval Midgut by Using Culturing and Culture-Independent Methods. Applied and Environmental Microbiology 70, 293300 DOI 10.1128/AEM.70.1.293-300.2004.

Buschke, N., Schröder, H. \&Wittmann, C. 2011. Metabolic engineering of Corynebacterium glutamicum for production of 1,5-diaminopentane from hemicellulose. Biotechnology Journal 6, 306-317 DOI 10.1002/biot.201000304.

Calderon-Cortes, N., Quesada, M., Watanabe, H., Cano-Camacho, H. \& Oyama, K. 2012. Endogenous Plant Cell Wall Digestion: A Key Mechanism in Insect Evolution. Annual Review of Ecology Evolution and Systematics 43, 45-71 DOI 10.1146/annurev-ecolsys-110411-160312

Caporaso, J.G., Kuczynski, J., Stombaugh, J., Bittinger, K., Bushman, F.D., \& Costello, E.K. 2010. QIIME allows analysis of high-throughput community sequencing data. Nature Methods 7, 335-336 DOI 10.1038/nmeth.f.303.

Davison, A. \& Blaxter, M. 2005. Ancient origin of glycosyl hydrolase family 9 cellulase genes. Molecular Biology and Evolution 22, 1274-1284 DOI 10.1093/molbev/msi107

Dillon, R. J. \& Dillon, V. M. 2004. The gut bacteria of insects: Nonpathogenic interactions. Annual Review of Entomology 49 , 71-92 DOI 10.1146/annurev.ento.49.061802.123416.

Dillon, R. J., Vennard, C. T. \& Charnley, A. K. 2002. A note: gut bacteria produce components of a locust cohesion pheromone. Journal of Applied Microbiology 92, 759-763 DOI 10.1046/j.1365-2672.2002.01581.x

Dillon, R. J., Webster, G., Weightman, A. J. \& Charnley, A. K. 2010. Diversity of gut microbiota increases with aging and starvation in the desert locust. Antonie Van Leeuwenhoek International Journal of General and Molecular Microbiology 97, 69-77 DOI 10.1007/s10482-009-9389-5.

Douglas, A.E. 2009. The microbial dimension in insect nutritional ecology. Funct Ecol. 23, 38-47 DOI 10.1111/j.13652435.2008.01442.x.

Edgar, R. C. 2010. Search and clustering orders of magnitude faster than BLAST. Bioinformatics 26, 460-2461 DOI 10.1093/bioinformatics/btq461.

Engel, P. \& Moran, N. A. 2013. The gut microbiota of insects - diversity in structure and function. FEMS Microbiology Reviews 37,699-735 DOI 10.1111/1574-6976.12025.

Fang, L., Kuang, L.Y. \& Niu, Z.T. 2009. A Study on Intake and Digestion of 4 Straw Diets for Xinjiang Donkey. Journal of Xinjiang Agricultural University 32 , 45-48 DOI 10.3969/j.issn.1007-8614.2009.03.010.

Gichuhi, J., Sevgan, S., Khamis, F., Van den Berg, J., du Plessis, H., Ekesi, S. \& Herren, JK. 2020. Diversity of fall armyworm, Spodoptera frugiperda and their gut bacterial community in Kenya. PeerJ 8, e8701 DOI 10.7717/peerj.8701

Guo, J., Wu, J., Deng, Y. X., Lin, L. B., Liu, S. \& Li, J. L. 2015. Advances in research on insect gut microbiota and their functions. Chinese Journal of Applied Entomology 52,1345-1352 DOI 10.7679/j.issn.2095-1353.2015.06.004.

Hancock, P. A., Sinkins, S. P., Godfiiray, H. \& Godfry, C. J. 2011. Strategies for introducing Wolbachia to Reduce Transmission of Mosquito-Borne Diseases. Plos Neglected Tropical Diseases 5, e1024 DOI 10.1371/journal.pntd.0001024.

Hendriks, A. T. W. M. \& Zeeman, G. 2009. Pretreatments to enhance the digestibility of lignocellulosic biomass. Bioresource Technology 100, 10-18 DOI 10.1016/j.biortech.2008.05.027

Ibanez, S.,Lavorel,S., Puijalon, S. \& Moretti, M. 2013. Herbivory mediated by coupling between biomechanical traits of plants

Peer] reviewing PDF | (2020:05:49060:2:0:NEW 19 Sep 2020) 
504

505

506

507

508

509

510

511

512

513

514

515

516

517

518

519

520

521

522

523

524

525

526

527

528

529

530

531

532

533

534

535

536

537

538

539

540

541

542

and grasshoppers. Functional Ecology 27, 479-489 DOI 10.1111/1365-2435.12058.

Jehmlich, N., Muller, M., Meyer, S., Tischer, A., Potthast, K., Michalzik, B. \& von Bergen, M. 2016. Proteome data on the microbial microbiome of grasshopper feces. Date in Brief 9, 1147-1154 DOI 10.1016/j.dib.2016.11.033

Kostic A. D., Gevers D., Siljander H., Vatanen T., Hyotylainen T., Hamalainen A. M., Peet A., Tillmann V., Poho P., Mattila I., Lahdesmaki H., Franzosa E. A., Vaarala O., De Goffau M., Harmsen H., Ilonen J., Virtanen S.M., Clish C. B., Oresic M., Huttenhower C., Knip M. \&Xavier R. J. 2015. The dynamics of the human infant gut microbiome in development and in progression toward type 1 diabetes. Cell Host and Microbe 17, 260-273 DOI 10.1016/j.chom.2015.01.001

Kundu, P., Manna, B., Majumder, S. \& Ghosh, A. 2019. Species-wide Metabolic Interaction Network for Understanding Natural Lignocellulose Digestion in Termite Gut Microbiota. Scientific Reports 9, 1-13 DOI 10.1038/s41598-019-52843-w

Lavy, O., Gophna, U., Gefen, E. \& Ayali, A. 2019. The effect of density-dependent phase on the locust gut bacterial composition. Frontiers in Microbiology 10, 1-8 DOI 10.3389/fmicb.2018.03020.

Li, W. J., Meng, L., Qiu, J., An, S. Z., Chen, A. L. \& Wang, J. Y. 2000. Effects of different Utilization of Corn Straw on digestion and metabolism of Sheep. Herbivorous Livestock 13, 55-62 DOI 10.16863/j.cnki.1003-6377.2000.s1.013.

Liu, H. 2012. Research for Symbiotic bacteria community structure in gut of Termite and Locust. Thesis, Henan Agricultural University.

Liu, L.Y. \& Chen, H. Z. 2007. Establishment of (NIRS) method for determination of Corn Straw components by near Infrared diffuse Reflectance Spectroscopy. Spectroscopy and Spectral Analysis 27, 275-278 DOI 10.3964/j.issn.10000593.2007.02.018.

Liu, X. G., Yang, Y. J., Liao, Q. J., Xu, H. X., Liu, Y. H. \& Lu, Z. X. 2016. Analysis of the bacterial community structure and diversity in the intestine of Cnaphalocrocis medinalis (Lepidoptera: Pyralidae). Acta Entomologica Sinica 59,965-976 DOI 10.16380/j.kcxb.2016.09.006.

Mason, C. J., Lowe-Power, T. M., Rubert-Nason, K. F., Lindroth, R. L. \& Raffa, K. F. 2016. Interactions between Bacteria And Aspen Defense Chemicals at the Phyllosphere Herbivore Interface. Journal of Chemical Ecology 42, 193-201 DOI 10.1007/s10886-016-0677-z.

Mason, C. J., Jones, A. G. \& Felton, G. W. 2019. Co-option of microbial associates by insects and their impact on plantfolivore interactions. Plant Cell and Environment 42, 1078-1086 DOI 10.1111/pce.13430.

McNeil, S. \& Southwood, T.R.E. 1978. The role of nitrogen in the development of insect/plant relationships. Biochemical Aspects of Plant and Animal Coevolution. Academic Press, London 8, 32-37.

Min, F., Li, D. M., Xia, R. Y., Du, H. Y., Li, H. M. \& Xiong, J. H. 2017. Study on major components of Wheat Seedling. Journal of Nutrition 39, 99-101 DOI 10.13325/j.cnki.acta.nutr.sin.2017.01.021.

Mori, H., Maruyama, F., Kato, H., Toyoda, A., Dozono, A. \& Ohtsubo, Y. 2014. Design and experimental application of a novel non-degenerate universal primer set that amplifies prokaryotic 16S rRNA genes with a low possibility to amplify eukaryotic rRNA genes. DNA Research 21, 217-227 DOI 10.1093/dnares/dst052

Mueller-Hagedorn, A. \& Bockhorn, H. 2007. Pyrolytic behaviour of different biomasses (angiosperms) (maize plants, straws, and wood) in low temperature pyrolysis. Journal of Analytical and Applied Pyrolysis 79, 136-146 DOI 10.1016/j.jaap.2006.12.008

Muhammad, A., Fang, Y., Hou, Y. \& Shi, Z. 2017. The gut entomotype of red palm weevil Rhynchophorus ferrugineus Olivier (Coleoptera: Dryophthoridae) and their effect on host nutrition metabolism. Frontiers in Microbiology 8 DOI 10.3389/fmicb.2017.02291.

Peer] reviewing PDF | (2020:05:49060:2:0:NEW 19 Sep 2020) 
543 Potrikus C J, Breznak J A. 1977. Nitrogen-fixing Enterobacter Agglomerans isolated from guts of wood-eating termites.

544 Applied and Environmental Microbiology 33, 392-399 DOI 10.1128/AEM.33.2.392-399.1977.

545 Priya, N. G., Ojha, A., Kajla, M. K., Raj, A. \& Rajagopal, R. 2012. Host plant induced variation in gut bacteria of

546 Helicoverpa armigera. PLoS One 7, e30768 DOI 10.1371/journal.pone.0030768.

547 Rangberg, A., Diep, D. B., Rudi, K.\& Amdam, G. V. 2012. Paratransgeneisis: an approach to improve colony health and

548 molecular insight in hgoney bees (Apis mellifera)?. Integrative \& Comoarative Biology 52, 89-99 DOI 10.1093/icb/ics089.

549 San Yu, S., Ko Latt, Z., Phyu Kyaw, E. \& Mar Lynn, T. 2011. Accumulation of ammonia in culture broth by wild-type

550 nitrogen-fixing bacterium, Stenotrophomonas maltophila. International Journal of Applied Biology and Pharmaceutical

551 Technology 19, 1-13 DOI 10.13140/RG.2.1.2083.2246.

552

553

554

Schmid, R. B., Lehama, R. M., Brozel, V. S. \& Lundgren, J. G. 2015. Gut Bacterial Symbiont Diversity within Beneficial

555 Insects Linked to Reductions in Local Biodiversity. Annals of the Entomological Society of America 108, 993-999 DOI 10.1093/aesa/sav081.

Senior, P.J. 1975. Regulation of nitrogen metabolism in Escherichia coli and Klebsiella aerogenes: studies with the continuous

556 culture technique. Journal of Bacteriology 2, 407-418 DOI 10.1128/jb.123.2.407-418.

557

558

559

Shil, R. K., Mojumder, S., Sadida, F. F., Uddin, M. \& Sikdar, D. 2014. Isolation and identification of cellulolytic bacteria from the gut of three phytophagus insect species. Brazilian Archives of Biology and Technology 57, 927-932 DOI

560 10.1590/S1516-8913201402620.

561

Shu, R. H., Lu, S. L. \& Xu, X. L. 2011. Interaction of Biogenic Amines Produced by Enterococcus faecalis and Enterococcus

562 faecium. Food and Fermentation Industry 37, 16-20.

563

Su, L. J., Liu, H., Li, Y., Zhang, H. F., Chen, M., Gao, X. H., Wang, F. Q. \& Song, A. D. 2014. Cellulolytic activity and

564 structure of symbiotic bacteria in locust guts. Genetics and Molecular Research 13, 7926-7936 DOI

565 10.4238/2014.September.29.6.

Sun, J. Z. \& Chen, C. R. 2010. Cellulolytic insects and their potentials for viable biofuels: a new frontier discipline in Entomology and Bioengineering. Chinese Bulletin of Entomology 47,1033 -1042 DOI 10.7679/j.issn.2095-1353.2010.189.

Sun, W. J. 2014. Study on the fixation technology of mulberry leaf tea and its antioxidant effects in Vitro. Thesis, Southwest University.

570

571

Tan, S. Q., Yin, Y., Cao, K. L., Zhao, X. X., Wang, X. Y., Zhang, Y. X. \& Shi, W. P. 2020. Effects of a combined infection with Paranosema locustae and Beauveria bassianaon Locusta migratoriaand its gut microflora. Insect science. DOI $10.1111 / 1744-7917.12776$

573

Thompson, D. N., Houghton, T. P., Lacey, J. A., Shaw, P. G., Hess, R. S. 2003. Preliminary investigation of fungal bioprocessing of wheat straw for production of straw-thermoplastic composites. Applied Biochemistry and Biotechnology 105, 423-436 DOI 10.1385/abab:106:1-3:423

Vargas, M., Weiss, J. \& Mcclements, D. J. 2007. Adsorption of protein-coated, lipid droplets to mixed biopolymer hydrogel surfaces:Role of biopolyiner diffusion. Langmuir 23, 13059-13065 DOI 10.1021/la701576u. Clavibacter michiganensis and methods of its identification and control. Postepy Mikrobiologii 5, 73-86 DOI 10.1007/s10658011-9812-4.

Wang, C. Z. 1997. Effects of gossypol and tannic acid on growth and digestive physiology of Helicoverpa armigera larvae. Acta Phytophlacica Sinica 24, 13-18 DOI 10.3321/j.issn:0577-7518.1997.01.003. 
582

583

584

585

586

587

588

589

590

591

592

593

594

595

596

597

598

599

600

601

602

603

604

605

606

607

608

609

610

611

612

613

614

615

616

617

618

619

620

Wang, J. H., Xiong, Z., Wang, F., Wang, X. J., Lin, W. D., Zhang, H. W. \& Li X. 2010. Isolation of Cellulase Producing Strains in Alimentary Canal of Yunnanacris yunnaneus. Hubei Agricultural Sciences 49, 874-878 DOI 10.3969/j.issn.04398114.2010.04.034.

Wang, L.X., Chen, W., Xie, G.L., \& Zhou, L. 2018. Isolation and Identification of Proisotoma ananevae Intestinal Bacteria and Screening of Cellulose-degrading Bacteria. Journal of Insect 7, 835-842 DOI 10.16380/j.kcxb.2018.07.010.

Wang, T. W., Liu, Q. \& Chen, Z. Q. 2008. Test on oriental migratory locusts with different foods in captivity. Shandong Agricultural Sciences 5, 82-83 DOI 10.3969/j.issn.1001-4942.2008.05.024.

Warnecke, F., Luginbuhl, P., Ivanova, N., Ghassemian, M., Richardson, T. H., Stege, J. T., Cayouette, M., McHardy, A. C., Djordjevic, G., Aboushadi, N., Sorek, R., Tringe, S. G., Podar, M., Martin, H. G., Kunin, V., Dalevi, D., Madejska, J., Kirton, E., Platt, D., Szeto, E., Salamov, A., Barry, K., Mikhailova, N., Kyrpides, N. C., Matson, E. G., Ottesen, E. A., Zhang, X. N., Hernandez, M., Murillo, C., Acosta, L. G., Rigoutsos, I., Tamayo, G., Green, B. D., Chang, C., Rubin, E. M., Mathur, E. J., Robertson, D. E., Hugenholtz, P. \& Leadbetter, J. R. 2007. Metagenomic and functional analysis of hindgut microbiota of a wood-feeding higher termite. Nature 450, 560-565 DOI 10.1038/nature06269.

Willis, J. D., Klingeman,W. E., Oppert, C. Oppert, B. \& Jurat-Fuentes, J. L. 2010. Characterization of cellulolytic activity from digestive fluids of Dissosteira carolina (Orthoptera: Acrididae). Comparative Biochemistry and Physiology Part B: Comparative Biochemistry 157, 267-272 DOI 10.1016/j.cbpb.2010.06.012.

Xia, X., Zheng, D., Zhong, H., Qin, B., Gurr, G. M. \& Vasseur, L. 2013. DNA Sequencing Reveals the Midgut Microbiota of Diamondback Moth, Plutella xylostella (L.) and a Possible Relationship with Insecticide Resistance. Plos One 8, e68852 DOI 10.1371/journal.pone.0068852.

Xiang, H. \& Huang, Y. P. 2008. Symbiosis between gut microbiota and insects. Chinese Bulletin of Entomology 45,687-693 DOI 10.7679/j.issn.2095-1353.2008.149.

Xiong, S. M., Zuo, X. F. \& Zhu, Y. Y. 2005. Determination of cellulose, hemicellulose and lignin in rice hull. Cereal \& Feed Industry 8,40-41 DOI 10.3969/j.issn.1003-6202.2005.08.018.

Yi, F. P., Wang, L. L., Zhou, C., Chen, J. L., Zhang, J. F. \& Zhou, Z. Y. 2001. Studies on obligate aerobes in the intestines of silkworm. Journal of Southwest Agricaltural University 23, 117-119 DOI 10.3969/j.issn.1673-9868.2001.02.007.

Zhang, G., Zeng, G., Cai, X., Deng, S., Luo, D. \& Sun, G. 2007. Brachybacterium zhongshanense sp. nov., a cellulosedecomposing bacterium from sediment along the Qijiang River, Zhongshan City, China. International Journal of Systematic and Evolutionary Microbiology 57, 519-524 DOI 10.1099/ijs.0.64968-0.

Zhang, H. M., Zhen, R. P., Chen, J. W, \& Huang, H. 2010. Determination of lignocellulose components by NREL. Chinese Journal of Analysis Laboratory 29, 15-18 DOI 10.13595/j.cnki.issn1000-0720.2010.0297.

Zhang, W., He, Z. B., Deng, X. P. \& Yin, Y. P. 2005. Variety and distribution of intestinal flora of apriona germori(hope) larvae. Journal of Southwest Agricultural University (Natural Science) 36, 209-212 DOI 10.3969/j.issn.16739868.2004.02.021.

Zhao, C. 2015. Study on the feeding ability on maize straw of Locusta migratoria manilensis (Megen). Thesis, Shandong Agricultural University.

Zheng, H., Perreau, J., Powell, J.E., Han, B.F., Zhang, Z.J., Kwong, W.K., Tringe, S.G. \& Moran, N.A. 2019. Division of labor in honey bee gut microbiota for plant polysaccharide digestion. Proceedings of the National Academy of Sciences of the United States of America 116, 25909-25916 DOI 10.1073/pnas.1916224116

Zhou, H. Y., Sun, B., Wu, H. L., Hu, X. M., Hao, Y. \& Ye, J. M. 2015. Research Progress on Insect Intestinal Microbe Function 
621 and Silkworm Intestinal Microbe. Northern Sericulture 36, 1-4+33 DOI 10.3969/j.issn.1673-9922.2015.04.001 


\section{Figure 1}

The_results_of_OTU-Venn_analysis

(A) OTU Venn diagram among different species (B) Composition of common OTUs at the family level.

A

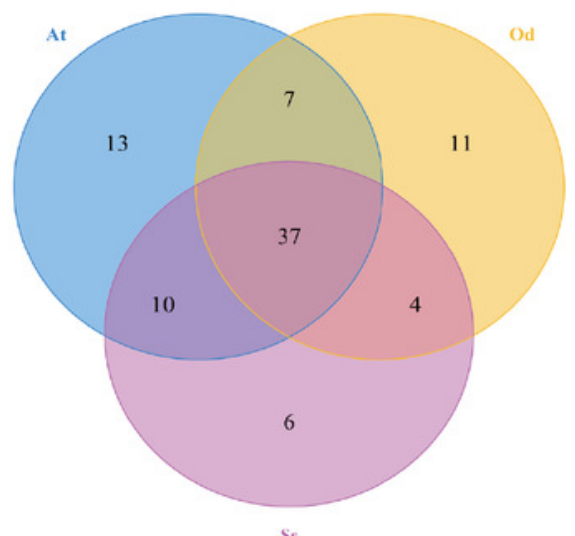

B

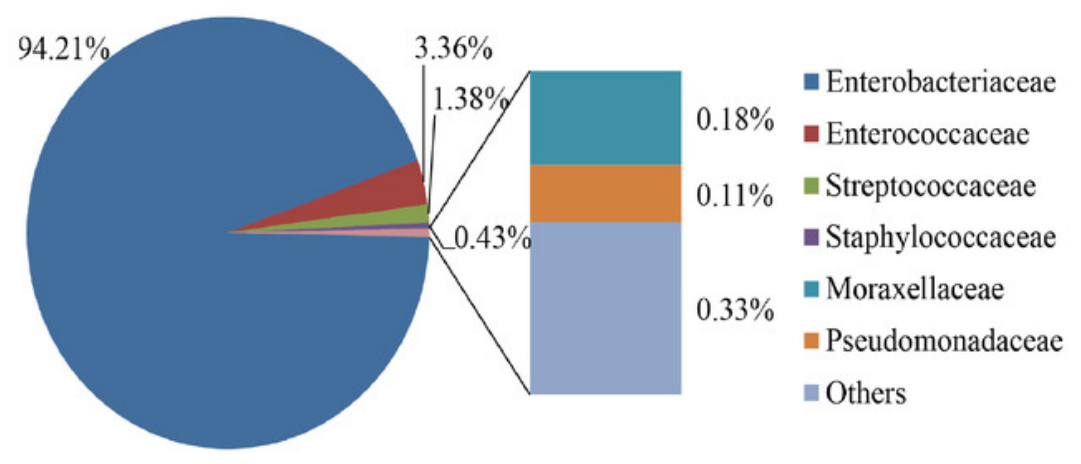




\section{Figure 2}

The results of $\alpha$-diversity analysis

(A) Rarefaction curves of 9 samples of grasshopper intestinal contents.(B) Species discovery curve. (A single blue box in this figure represents the total number of species detected in randomly selected samples. The cumulative curve is composed of the totality of blue boxes, which represents the rate of new species appearing under continuous sampling; a single purple box in this figure represents the number of common species detected in a given number of samples. The set of purple boxes form the common quantity curve, which represents the rate of common species detected under continuous sampling) (C) Chaol index of the three species grasshoppers (D) ACE index of the three species grasshoppers (E) Simpson index of three species grasshoppers (F) Shannon index of the three species grasshoppers. 

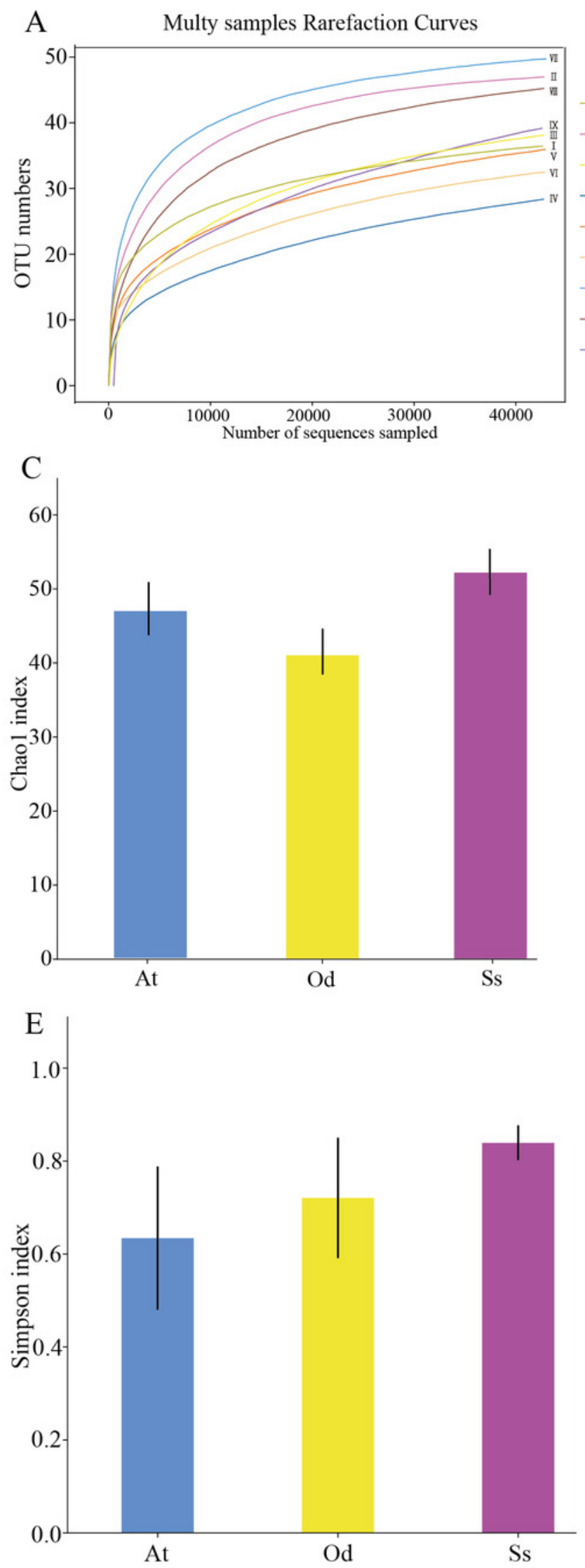

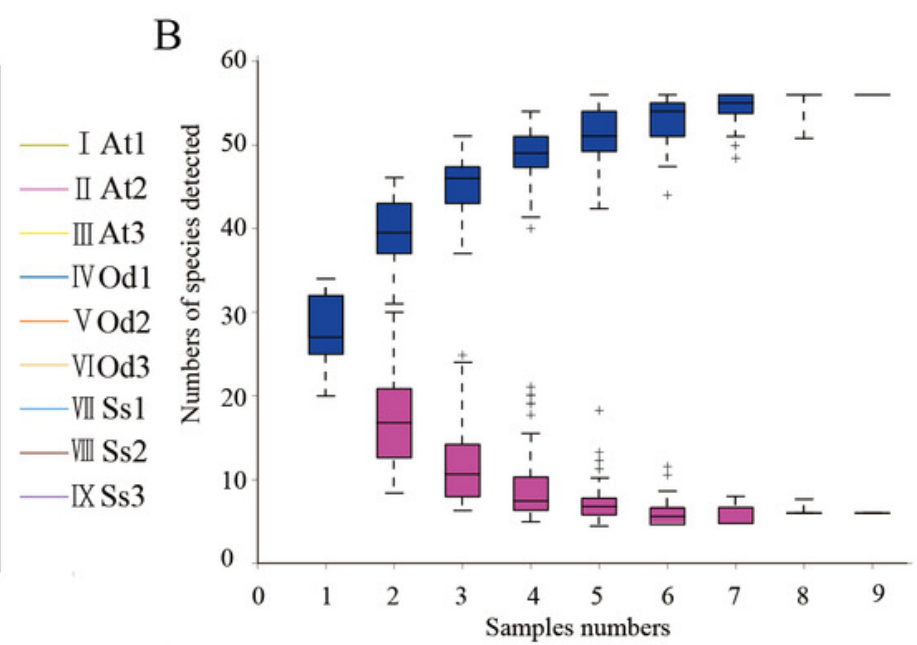

D
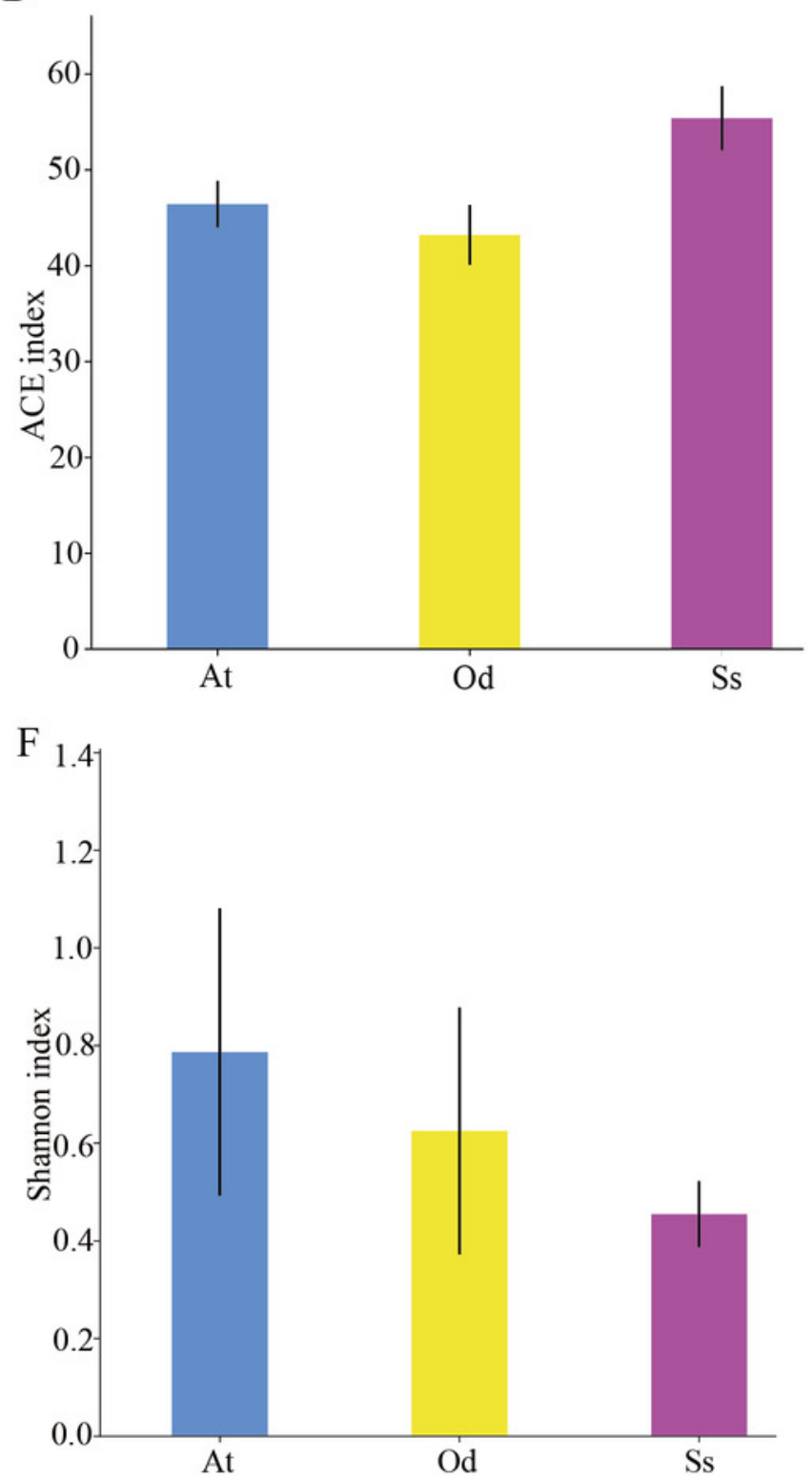
Figure 3

The_results_of_ $\beta$-diversity_analysis

(A) UPGMA cluster analysis of the three species grasshoppers (B) NMDS analysis based on the binary-jaccard distance (C) Heatmap of each sample at the OTU classification level (Blue indicate similarity and red indicate distance). 
A

Similarity

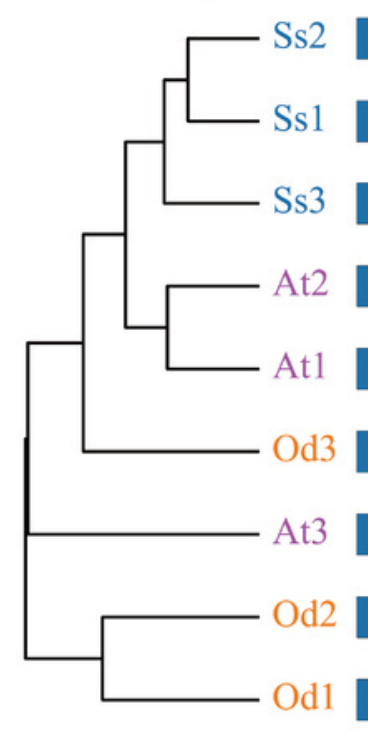

Taxonomic composition

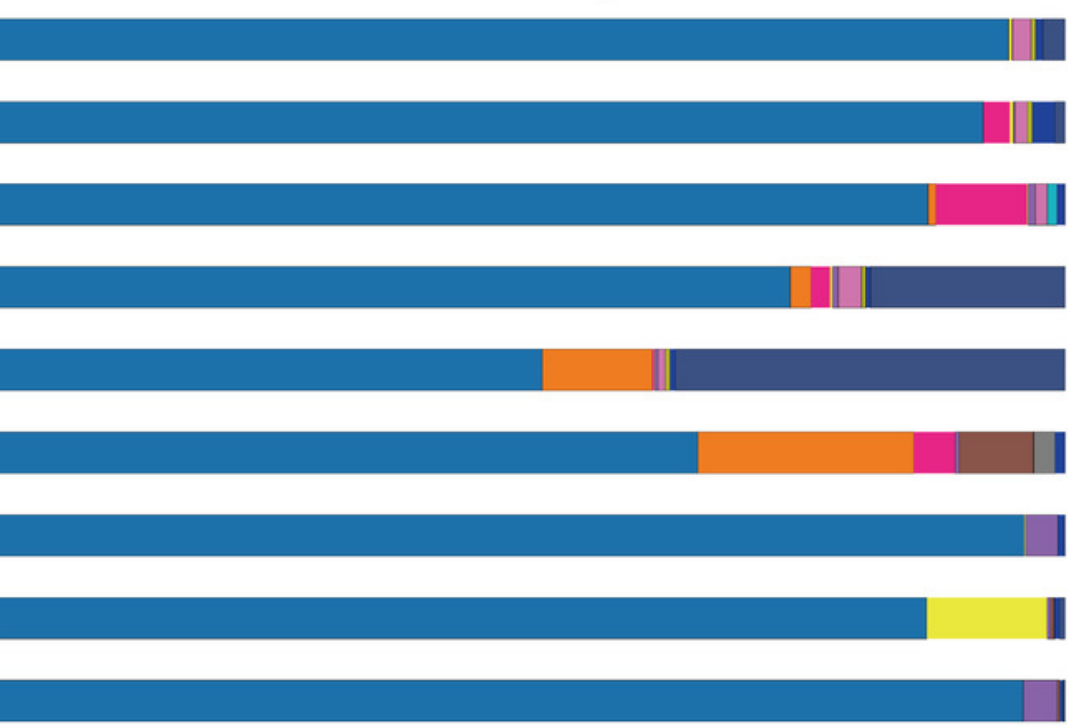

Taxa

Unclassified

Others

Pseudomonas

Acinetobacter

Weissella

Staphylococcus

Wolbachia

Enterobacter

Pantoea

Lactococcus

Enterococcus

Klebsiella

- Ss $\square \mathrm{Od} \square \mathrm{At}$

B

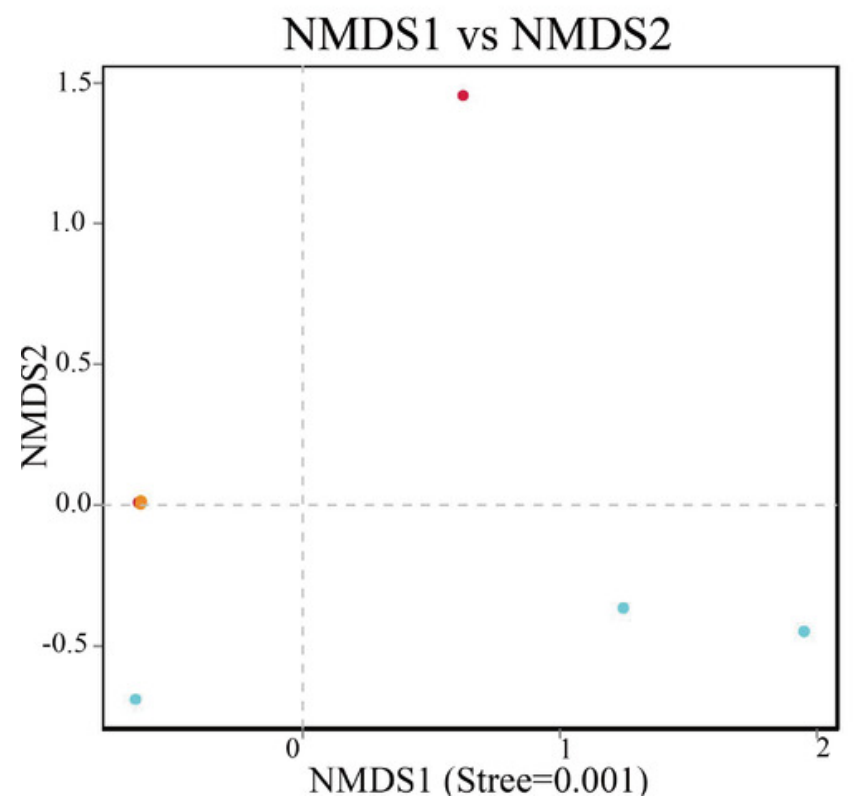

C

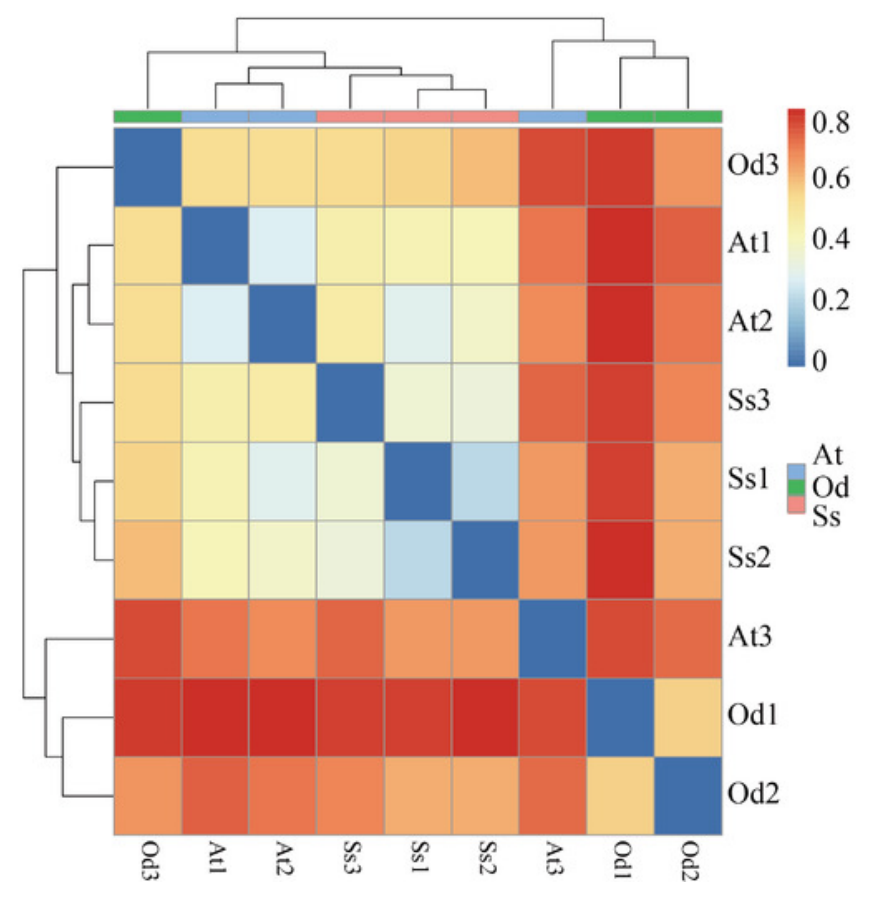




\section{Figure 4}

Diversity of the bacterial microbiota in the three species grasshoppers guts at the phylum $(A) / g e n u s(B)$ level
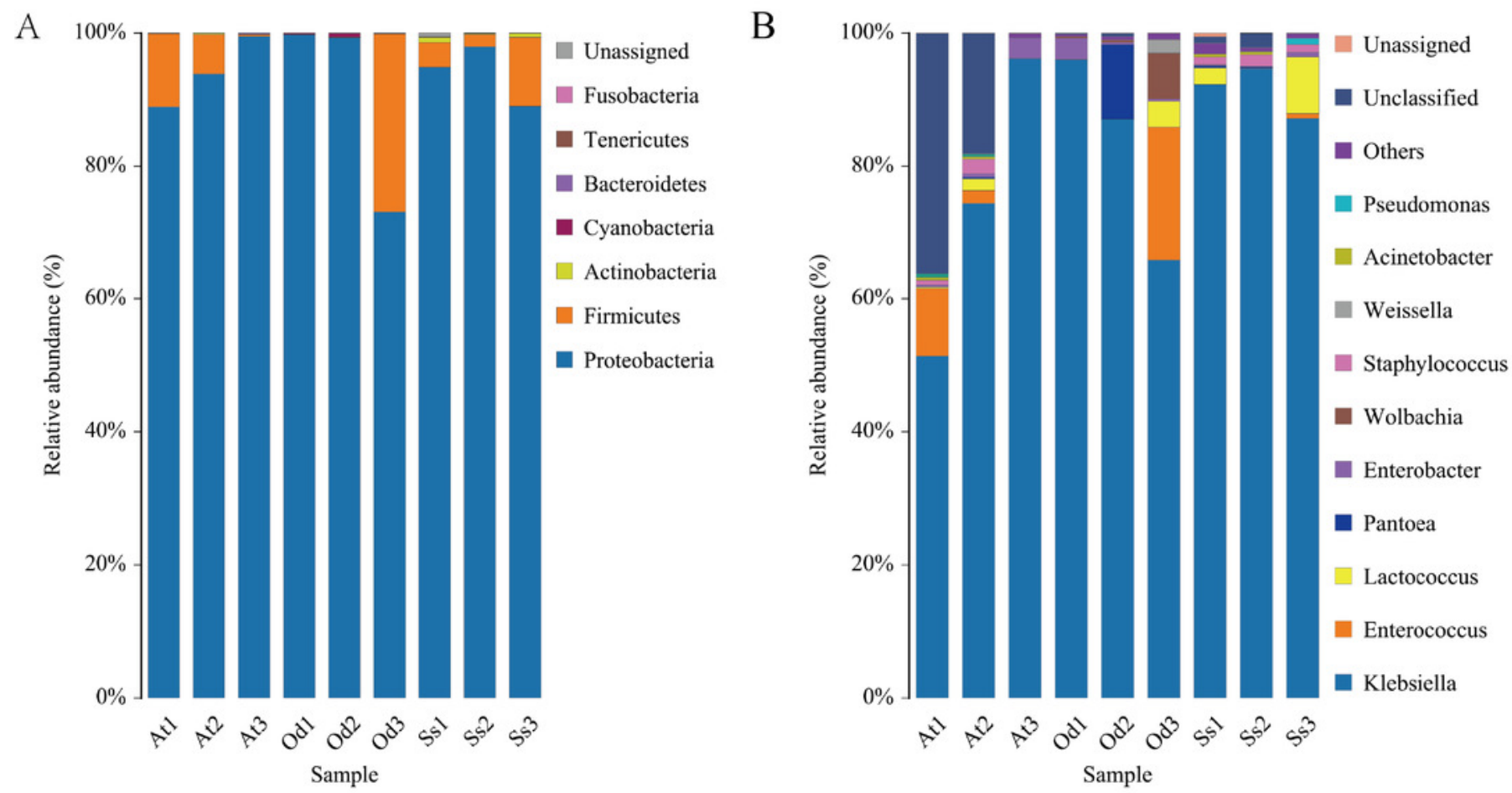


\section{Figure 5}

LEfSe analysis identifies biomarkers that cause differences between groups.

(A) Taxonomic cladogram obtained from LEfSe analysis of $16 \mathrm{~S}$ sequences and the brightness of each dot is proportional to its effect size. (B)Only taxa meeting an LDA significant threshold $>2$ are shown.

A Cladogram - Ss

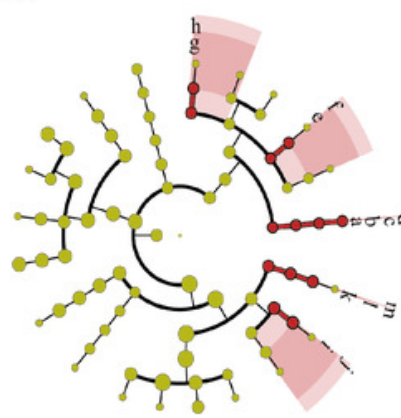

B

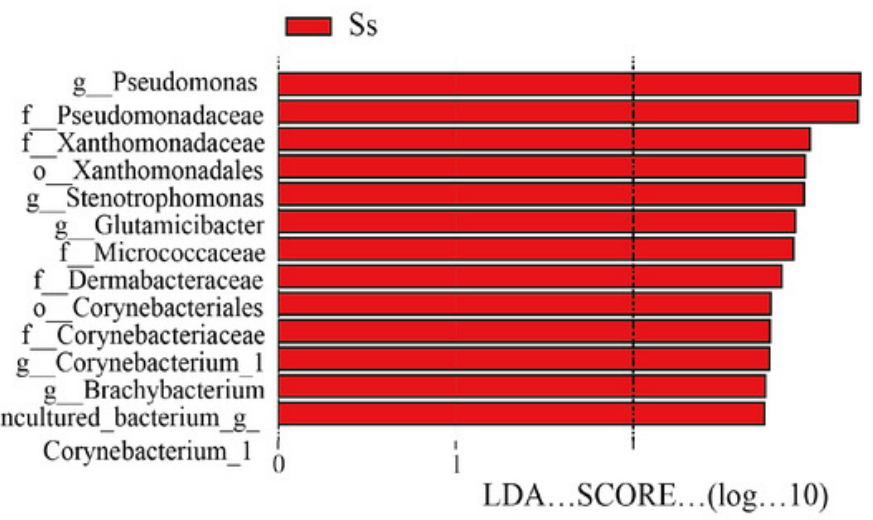




\section{Figure 6}

Heatmapofthe correlation between digestibilityandbacterial abundance.

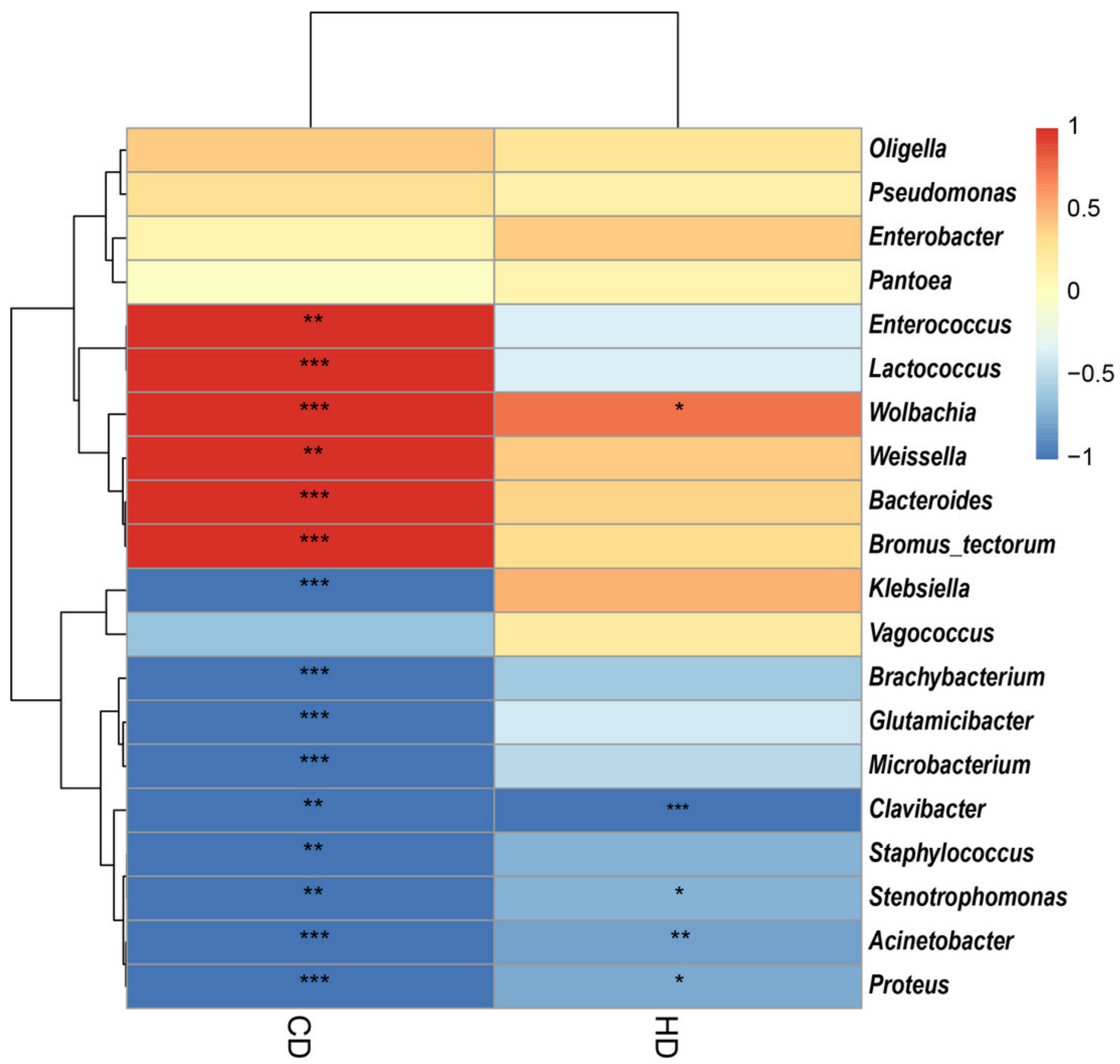


Table $\mathbf{1}$ (on next page)

Information on the studied samples 
1

Table 1. Information on the studied samples

\begin{tabular}{ccccc}
\hline Species & Sample code & No. of specimens & Locality & Collection date \\
\hline Aiolopus tamulus & At1 & 10 & Baoding, China & July 15, 2018 \\
& At2 & 10 & Baoding, China & July 15, 2018 \\
& At3 & 11 & Baoding, China & October 1, 2018 \\
Oedaleus decorus asiaticus & Od1 & 10 & Baoding, China & October 1, 2018 \\
& Od2 & 10 & Baoding, China & October 1, 2018 \\
& Od3 & 12 & Baoding, China & July 15, 2018 \\
& Ss1 & 10 & Baoding, China & October 1, 2018 \\
& Ss2 & 10 & Baoding, China & October 1, 2018 \\
& Ss3 & 10 & Baoding, China & October 1, 2018 \\
\hline
\end{tabular}

2

3 


\section{Table 2 (on next page)}

Sequence and proportion results of each sample and bacterial identification results 
1

2

Table 2. Sequence and proportion results of each sample and bacterial identification results

\begin{tabular}{|c|c|c|c|c|}
\hline Sample & Clean tags & Effective tags & Proportion & Identification result \\
\hline At1 & 53704 & 53325 & $99.29 \%$ & 4 phyla, 7 classes, 11 orders, 18 families, 26 genera \\
\hline At2 & 51643 & 51479 & $99.68 \%$ & 5 phyla, 9 classes, 13 orders, 24 families, 31 genera \\
\hline At3 & 61063 & 61018 & $99.93 \%$ & 5 phyla, 10 classes, 17 orders, 28 families, 28 genera \\
\hline Od1 & 61047 & 61024 & $99.96 \%$ & 6 phyla, 9 classes, 12 orders, 18 families, 21 genera \\
\hline Od2 & 72346 & 72296 & $99.93 \%$ & 6 phyla, 9 classes, 16 orders, 23 families, 27 genera \\
\hline Od3 & 53117 & 52034 & $97.96 \%$ & 5 phyla, 7 classes, 11 orders, 17 families, 22 genera \\
\hline Ss1 & 52796 & 52631 & $99.68 \%$ & 5 phyla, 9 classes, 16 orders, 28 families, 32 genera \\
\hline Ss2 & 53296 & 53144 & $99.71 \%$ & 5 phyla, 8 classes, 15 orders, 25 families, 31 genera \\
\hline Ss3 & 53097 & 52485 & $98.85 \%$ & 5 phyla, 8 classes, 13 orders, 24 families, 30 genera \\
\hline Tatal & 512109 & 509436 & $99.48 \%$ & 7 phyla, 12 classes, 20 orders, 42 families, 54 genera \\
\hline
\end{tabular}

3 


\section{Table 3(on next page)}

Statistical results of the diversity index of the intestinal content samples of grasshoppers 
Table 3. Statistical results of the diversity index of the intestinal content samples of grasshoppers

\begin{tabular}{ccccccc}
\hline Simple ID & OTU & ACE & Chao1 & Simpson & Shannon & Coverage \\
\hline At1 & 37 & 41.5776 & 40.0000 & 0.3996 & 1.1721 & 0.9999 \\
At2 & 47 & 48.7316 & 48.2000 & 0.5780 & 0.9800 & 0.9999 \\
At3 & 41 & 48.9659 & 52.2500 & 0.9249 & 0.2079 & 0.9998 \\
Od1 & 31 & 41.2173 & 38.2000 & 0.9211 & 0.2320 & 0.9998 \\
Od2 & 40 & 49.3557 & 47.2000 & 0.7624 & 0.5464 & 0.9999 \\
Od3 & 33 & 39.0695 & 37.6667 & 0.4783 & 1.0977 & 0.9998 \\
Ss1 & 50 & 51.9067 & 50.8571 & 0.8528 & 0.4748 & 0.9999 \\
Ss2 & 46 & 52.1871 & 51.6000 & 0.8964 & 0.3283 & 0.9998 \\
Ss3 & 44 & 62.0907 & 54.1111 & 0.7679 & 0.5609 & 0.9997
\end{tabular}

2

3 


\section{Table 4 (on next page)}

Digestibility of cellulose and hemicellulose in wheat seedlings in three species grasshoppers

The data in the table are expressed as the mean standard error, and the data in the same column with different lowercase letters show significant difference $(P<0.05)$. 
1

Table 4. Digestibility of cellulose and hemicellulose in wheat seedlings in three species grasshoppers

\begin{tabular}{ccc}
\hline Sample & digestibility rate of cellulose & digestibility rate of hemicellulose \\
\hline Aiolopus tamulus & $43.95 \pm 2.02 \mathrm{a}$ & $17.21 \pm 2.98 \mathrm{~b}$ \\
Oedaleus decorus asiaticus & $38.01 \pm 3.96 \mathrm{a}$ & $24.99 \pm 4.80 \mathrm{~b}$ \\
Shirakiacris shirakii & $44.12 \pm 3.60 \mathrm{a}$ & $47.65 \pm 3.37 \mathrm{a}$
\end{tabular}

2 The data in the table are expressed as the mean standard error, and the data in the same column with different lowercase letters 3 show significant difference $(\mathrm{P}<0.05)$.

4 